\title{
COVID-19 associated psychological symptoms in Turkish population: A path model
}

\author{
Ayşegül Durak Batıgün ${ }^{1}$ · İpek Şenkal Ertürk ${ }^{1}$ (B) \\ Accepted: 20 June 2021 / Published online: 1 July 2021 \\ (C) The Author(s), under exclusive licence to Springer Science+Business Media, LLC, part of Springer Nature 2021
}

\begin{abstract}
We investigated the mediator roles of risk factors (intolerance of uncertainty, negative metacognition, and negative prospections) and protective factors (positive prospections and psychological resilience) together on the link between COVID-19-related feelings and behaviors, thoughts, and precautions taken and psychological symptoms with an integrative approach in Turkey. The online sample consisted of Turkish adults. The results of path analyses indicated that feelings and behaviors related to COVID-19, thoughts about COVID-19, and precautions taken related to COVID-19 are significantly associated with intolerance of uncertainty. Intolerance of uncertainty is significantly associated with negative metacognition, negative and positive prospections, psychological symptoms, and psychological resilience. Negative metacognition, negative and positive prospections, and psychological resilience are significantly associated with psychological symptoms. Mediation analysis demonstrated that intolerance of uncertainty significantly mediated the relationship between feelings and behaviors related to COVID-19, thoughts about COVID-19, and precautions taken related to COVID-19 and negative metacognition, psychological resilience, positive and negative prospections, and psychological symptoms. Lastly, negative metacognition, psychological resilience, positive and negative prospections significantly mediated the relationship between intolerance of uncertainty and psychological symptoms. Implications for mental health providers are discussed.
\end{abstract}

Keywords COVID-19 P Psychological symptoms · Negative metacognition · Psychological resilience $\cdot$ Intolerance of uncertainty $\cdot$ Prospections

\section{Introduction}

The novel coronavirus disease-2019 (COVID-19) has spread across the world within a few months. To date (June 1, 2021), there have been 171.916.845 people infected, 154.605 .572 people recovered, and 3.575.561 people who had died from the COVID-19 infection worldwide (Worldometer, 2021). These numbers have been respectively 5.256.516, 5.124.081, and 47.656 for Turkey (T. C. Ministry of Health, 2021). Thus, the COVID-19, one of the deadliest pandemics, has devastating effects on not only physical health but mental health as well (Arslan et al., 2020). It becomes considerably crucial to make an accurate assessment of the psychological

İpek Șenkal Ertürk

isenkal@ankara.edu.tr

Ayșegül Durak Batıgün

https://orcid.org/0000-0002-8278-6419

1 Faculty of Languages History and Geography, Department of Psychology, Ankara University, PC: 06100 Sihhiye, Ankara, Turkey effects, which may occur during and after the pandemic, for the proper interventions in the future (Çakıroğlu et al., 2020). Since COVID-19 has an unknown and complex nature, people encounter unprecedented uncertainties, resulting in psychological distress (Choi et al., 2020). For instance, it is considerably unpredictable that when the threat associated with this pandemic will disappear and we will return to normal. A high degree of uncertainty worldwide sustains due to the unprecedented nature of the COVID-19 pandemic, and it may be difficult for some people to tolerate these uncertainties (Rettie \& Daniels, 2020). In addition to the uncertainty about the course of the COVID-19 pandemic and its treatment, the probability of individuals themselves and the loved ones will get infected by the virus might increase anxiety levels (Çakıroğlu et al., 2020). Additionally, people have been constantly in an emotional, mental, and behavioral struggle regarding the pandemic itself and its negative consequences. For instance, they might be in emotional distress (e.g., fearful, anxious, angry, upset), have thoughts about the COVID-19 pandemic (e.g., after this pandemic, nothing will be the same as before), and display behaviors related to COVID-19 pandemic (e.g., 
checking the symptoms frequently) (Durak Batıün \& Șenkal Ertürk, 2020).

Intolerance of uncertainty is best described as a predisposition to find uncertainty unacceptable (Buhr \& Dugas, 2002). Considering the studies about the intolerance of uncertainty in the context of its relationship with psychopathology, generalized anxiety disorder has been emphasized (e.g., Dugas et al., 2005; Rettie \& Daniels, 2020). Further, it was shown that there was a positive correlation between intolerance of uncertainty and health anxiety (Kraemer et al., 2016). It has been also suggested that intolerance of uncertainty has played a significant role in many psychological disorders such as obsessive-compulsive disorder (Lind \& Boschen, 2009) and social anxiety (Boelen \& Reijntjes, 2009). Especially, intolerance of uncertainty was regarded as a salient cognitive risk factor for anxiety states (Carleton, 2012). These findings suggest that as intolerance of uncertainty may be a pivotal risk factor in many anxiety symptoms, including health anxiety, this psychological concept should be considered when studying the COVID-19 pandemic.

Another cognitive factor, which plays a significant role in the development and maintenance of excessive worry, is negative metacognition (Thielsch et al., 2015). Worry and other intrusive thoughts probably increase in stressful times, and they could affect the endorsement of beliefs regarding mental control (Wells \& Cartwright-Hatton, 2004). Additionally, anxietyrelated cues trigger metacognitive beliefs, thought to initiate worry as a coping method (Thielsch et al., 2015). Thus, it is thought that negative metacognition could be considered as a significant cognitive risk factor against psychological symptoms in the process of COVID-19 outbreak, which activates stress and anxiety states by increasing uncertainty. Wells and Papageorgiou (1998) found that metacognitions are also positively associated with pathological worry symptoms. Longitudinal analysis in a survey study showed that metacognition was the best predictor of future anxiety symptoms compared to automatic thoughts (Hjemdal et al., 2013).

Another precursor of psychological symptoms could also be negative prospections. Initially, prospection described as the mental representation of possible futures is an omnipresent characteristic of the human mind (Seligman et al., 2013). Negative prospections, regarded as a cognitive risk factor against psychological symptoms during the COVID-19 pandemic, seem to be closely associated with depression symptoms (Roepke \& Seligman, 2016; Strunk et al., 2006). Above all, this inference was built upon Beck's (1974) negative cognitive triad, a negative view of the world, the self, and maybe the foremost, of the future (Roepke \& Seligman, 2016). Furthermore, studies conducted on negative prospections have shown that along with depression, negative prospections were related to negative affect, anxiety, hopelessness, worry (MacLeod et al., 1996), negative automatic thoughts, and dysfunctional attitudes (Ergüler \& Durak Batıgün, 2018).
In addition to the risk factors mentioned so far, it is thought that studying personal factors thought to protect people against psychological symptoms in the context of the COVID-19 pandemic will be a significant contribution to the related literature. More specifically, it is crucial to identify psychological risk factors as well as protective factors to reduce the psychological effects of such a deadly pandemic, COVID-19. At this point, positive prospections and psychological resilience come to the fore. Positive prospections refer to positive expectations about the future (MacLeod et al., 1996). The ability to direct behavior positively toward the future is thought to be an acquired skill that has to be learned (Reading, 2004). It was found that an intervention aimed to increase positive expectations about the future reduced the symptoms of major depressive disorder (Vilhauer et al., 2012). Consistently, a study conducted about future-oriented thinking has shown that aspiring for a positive future distinctively predicted well-being (Sohl \& Moyer, 2009). Psychological resilience, as another cognitive protective factor against psychological symptoms during the COVID-19 pandemic, is described as the process of adapting to trauma, stress, tragedy, threats, or adversity well and includes both "bouncing back" from these stressful situations and broad personal growth (American Psychological Association, 2012). Considering the context of the COVID-19 pandemic, an unfamiliar and chaotic situation, psychological resilience is an ability of a person to manage his/her sense of responsibility in such a situation (Di Monte et al., 2020). Psychological resilience, regarded as a character strength, promotes positive functioning and optimal development while inhibiting negative emotions, thoughts, and behaviors (Yıldırım \& Solmaz, 2020). Studies about psychological resilience have indicated that psychological resilience was negatively associated with psychological symptoms, including depression, anxiety (Hu et al., 2020; Ran et al., 2020; Smith et al., 2008), somatic symptoms (Ran et al., 2020), fear (Hu et al., 2020), negative affect, perceived stress (Smith et al., 2008), and posttraumatic stress (Luceño-Moreno et al., 2020).

\section{The Present Study}

Present study aimed to investigate both risk factors (intolerance of uncertainty, negative metacognition, and negative prospections) and protective factors (positive prospections and psychological resilience) against psychological symptoms with an integrative approach during the COVID-19 pandemic. More specifically, we aimed to examine the link between COVID-19-related feelings and behaviors, thoughts, and precautions taken and psychological symptoms among Turkish adults. For this purpose, we hypothesized that (a) COVID-19related feelings and behaviors, thoughts, and precautions taken would directly predict intolerance of uncertainty, (b) intolerance of uncertainty would directly predict negative 
metacognition, psychological symptoms, psychological resilience, positive prospections, and negative prospections, (c) negative metacognition, psychological resilience, positive prospections, and negative prospections would directly predict psychological symptoms, (d) intolerance of uncertainty would play a mediating role in the relationship between COVID-19-related feelings and behaviors, thoughts, and precautions taken and negative metacognition, psychological symptoms, psychological resilience, positive prospections, and negative prospections, and (e) negative metacognition, psychological resilience, positive prospections, and negative prospections would mediate the link between intolerance of uncertainty and psychological symptoms.

\section{Method}

\section{Sample and Procedure}

The research data were collected via Surveey, an online survey system, from May to September 2020. Data were recruited through the convenience sampling technique (Dörnyei, 2007). A cross-sectional design was employed to investigate the purpose of the study. Questionnaires were administered to volunteer adult participants in Turkey $(N=542)$. The inclusion criterion for the study was that participants had to be between 18 and 64 years. From the 542 participants, three were excluded due to violation of inclusion criteria, one was excluded due to missing response and two were excluded due to outlier analysis. The remaining participants $(N=536)$ had a mean age of 36.57 years $(S D=12.64)$. Among the participants, $72.9 \%$ were females and $27.1 \%$ were males. The required permission was obtained from Ankara University Ethics Committee, and informed consent was obtained from all participants before participation. With the Informed Consent Form, the participants were informed about the general purpose of the study. It was stated that the information obtained would be kept confidential, and they could refrain from continuing at any time. Participants accessed the scales via a link. Information about the descriptive characteristics of the study participants was demonstrated in Table 1.

\section{Measures}

\section{Demographic Information Form}

The authors prepared this form to acquire information about the participants' socio-demographic characteristics such as age, gender, education, and information about COVID-19 experiences.
Table 1 Demographic characteristics of the participants

\begin{tabular}{lll}
\hline & $n$ & $\%$ \\
\hline Gender & 391 & 72.9 \\
Female & 145 & 27.1 \\
Male & & \\
Education level & 6 & 11.0 \\
Primary education & 40 & 7.5 \\
High school & 490 & 91.4 \\
Undergraduate and graduate & & \\
Participant got test for COVID-19 & 40 & 7.5 \\
Yes & 496 & 92.5 \\
No & & \\
Relatives with COVID-19 diagnosis & 163 & 30.4 \\
Yes & 373 & 69.6 \\
No & & \\
Relatives who died for COVID-19 & 44 & 8.2 \\
Yes & 492 & 91.8 \\
No &
\end{tabular}

\section{Multi-Dimensional COVID-19 Scale}

This scale is a 22-item with a 5-point Likert-type self-report scale developed in Turkish by Durak Batıgün and Șenkal Ertürk (2020) to determine the feelings, thoughts, and behaviors associated with COVID-19 and the precautions individuals take against this virus. This scale consists of three subscales: "Feelings and behaviors related to COVID-19" (e.g., "This pandemic makes me too anxious"; "I am constantly following the news about the pandemic"), "Thoughts about COVID-19" (e.g., "I think this pandemic is quite serious") and "Precautions taken related to COVID-19" (e.g., "I always wear a mask when I go out"). The first subscale, "Feelings and behaviors related to COVID-19", simply assesses emotions such as sadness, fear, anxiety and anger related to the pandemic, and behaviors such as checking the symptoms, following news about the pandemic and talking about the pandemic often. The second subscale, "Thoughts about COVID-19" describes the thoughts individuals have about the severity, duration and effects of the pandemic on daily life. The third subscale, "Precautions taken related to COVID-19", as the name suggests, refers to the precautions taken such as washing hands frequently, wearing masks, maintaining social distance and going out rarely. Cronbach's alpha for the total score is .90 and for these subscales are $.88, .77$, and .75 , respectively (Durak Batıün \& Şenkal Ertürk, 2020). The Cronbach's alpha calculated for the current study is .90 for the total score, for these subscales are $.88, .74$, and .76 , respectively. 


\section{Brief Symptom Inventory (BSI)}

BSI is a 53-item with a 4-point Likert-type self-report scale developed by Derogatis (1992) to evaluate a variety of psychological symptoms. Turkish adaptation of the scale was conducted on adults by Șahin and Durak (1994). This study reported that the scale consisted of five subscales called "anxiety", "depression", "negative self", "somatization" and "hostility". The Cronbach's alpha for these subscales are .87, .88, $.87, .75$ and .76, respectively (Șahin \& Durak, 1994). The Cronbach's alpha calculated for the current study is .90 for anxiety, .92 for depression, .91 for negative self, .87 for somatization, and .82 for hostility. Higher scores indicate a higher frequency of symptoms of the individual.

\section{Intolerance of Uncertainty Scale (IUS)}

IUS is a 27-item self-report and 5-point Likert-type scale developed in French to assess emotional, cognitive, and behavioral responses to ambiguous situations. Buhr and Dugas (2002) conducted an English adaptation of the scale. In Turkey, Sarı and Dağ (2009) adapted this scale into Turkish and they revealed that the scale has a four-factor structure, called "uncertainty is stressful and upsetting", "negative selfassessment about uncertainty", "disturbing thoughts about the uncertainty of future", and "uncertainty keeps someone from acting". Cronbach's alpha for the whole scale is .79, and for the subscales, it ranged between .79 and .88 (Sarı \& Dağ, 2009). Cronbach's alpha calculated for the present study is .95 for the total score, and for the subscales, it ranges between .83 and .91 .

\section{The Brief Resilience Scale (BRS)}

BRS is a 6-item with a 5-point Likert-type scale developed by Smith et al. (2008) and adapted into Turkish by Doğan (2015) to assess the psychological resilience of individuals. Cronbach's alpha coefficient was found to be .83 for the total scale (Doğan, 2015). Cronbach's alpha calculated for the current study is .86 for the total score. Higher scores on the scale indicate higher psychological resilience.

\section{Meta-Cognitions Questionnaire-30 (MCQ-30)}

The shortened 30-item version of the MCQ was developed by Wells and Cartwright-Hatton (2004) to assess different dimensions of metacognition. MCQ is a self-report, 4-point Likerttype scale and adapted into Turkish by Tosun and Irak (2008). The MCQ-30 includes five subscales: "positive beliefs", "cognitive confidence", "uncontrollability and danger", "cognitive self-consciousness" and "need to control thoughts". Cronbach's alpha for the total score is .86, and for the subscales, it ranged between .65 and .87 (Tosun \& Irak, 2008).
Cronbach's alpha for the present study is .87 for the total score, and for the subscales, it ranges between .69 and .87 . Higher scores on the scale indicate higher negative metacognition.

\section{Subjective Probability Task}

It is a scale consisting of 30 single-sentence statements with a 7-point Likert-type self-report scale developed by MacLeod et al. (1996) and adapted into Turkish by Ergüler and Durak Batıgün (2018). This scale consists of 20 negative and 10 positive statements about situations and events related to the individual's future (including the test day). While negative statements refer to negative prospections, positive statements refer to positive prospections. The scale has a two-factor structure, called positive prospections and negative prospections. Cronbach's alpha was .86 for the positive prospections and .90 for the negative prospections (Ergüler \& Durak Batıgün, 2018). The Cronbach's alpha calculated for the present study was .90 for the positive prospections and .94 for the negative prospections.

\section{Data Analysis}

Before statistical analyses, the presence of missing values, the assumptions of normality, and outliers were tested. Firstly, the data were checked for normality distribution (between +2.0 and - 2.0 values) (George \& Mallery, 2010). Secondly, outlier analysis was performed for a non-normally distributed variable (i.e., "precautions taken related to COVID-19" subscale). As a result of the analysis, univariate outliers were identified according to the $\mathrm{z}$ distribution $(|\mathrm{z}| \geq 3.29)$ until a normal distribution was obtained (Tabachnick \& Fidell, 2001), and the values of two participants were not included in the analysis. After it was assured that the data met the statistical assumptions, relationships between the study variables were investigated using Pearson's correlation analysis. Path analysis was run to test the hypothesized model. Furthermore, the mediational roles were analyzed using a bootstrapping method (2000 resamples) with $95 \%$ bias-corrected confidence intervals (BC CI) (Shrout \& Bolger, 2002). It is considered that if zero is not included in the CI for the estimate of the indirect effect, this effect is statistically significant at $p<0.05$ level (Shrout \& Bolger, 2002). All data analyses were performed using IBM SPSS Statistics v23 and AMOS v21 software.

\section{Results}

\section{Correlation Analysis}

Pearson's correlation analysis was employed to determine the relationships between the study variables. Descriptive 
statistics and Pearson's correlation coefficients for the study variables are presented in Table 2.

As seen in Table 2, feelings and behaviors related to COVID-19 $(r=.42, p<.001)$, thoughts about COVID-19 $(r=.33, p<.001)$ and precautions taken related to COVID$19(r=.16, p<.001)$ had significant and positive correlation with intolerance of uncertainty. Intolerance of uncertainty had significant and positive correlation with negative metacognition $(r=.59, p<.001)$, negative prospections $(r=.36$, $p<.001)$ and psychological symptoms $(r=.60, p<.001)$, as well as a significant and negative correlation with positive prospections $(r=-.19, p<.001)$ and psychological resilience $(r=-.47, p<.001)$. Lastly, while negative metacognition $(r=.51, p<.001)$ and negative prospections $(r=.48$, $p<.001)$ had a significant and positive correlation with psychological symptoms, positive prospections $(r=-.25$, $p<.001)$ and psychological resilience $(r=-.47, p<.001)$ had a significant and negative correlation with psychological symptoms.

\section{Path Analysis}

Path analysis was conducted to test the statistically significant links between COVID-19-related feelings and behaviors, thoughts, and precautions taken and psychological symptoms, and the mediating roles of intolerance of uncertainty, negative metacognition, psychological resilience, negative and positive prospections between these links. The fit indices for the model before and after the error associations are presented in Table 3.

As seen in Table 3, the model had acceptable goodness of fit values (see Hu \& Bentler, 1999; Tabachnick \& Fidell, 2001) after three error associations.

When the direct associations in the study model were examined (see Fig. 1), feelings and behaviors related to COVID- $19(\beta=.39, p<.001)$, thoughts about COVID-19 $(\beta=.14$, $p<.01)$ and precautions taken related to COVID-19 $(\beta=$ $-.12, p<.01)$ are significantly associated with intolerance of uncertainty. Intolerance of uncertainty is significantly associated with negative metacognition $(\beta=.59, p<.001)$, negative prospections $(\beta=.36, p<.001)$, positive prospections $(\beta=$ $-.19, p<.001)$, psychological symptoms $(\beta=.34, p<.001)$ and psychological resilience $(\beta=-.47, p<.001)$. Negative metacognition $(\beta=.15, p<.001)$, negative prospections $(\beta=.25, p<.001)$, positive prospections $(\beta=-.08, p<.05)$ and psychological resilience $(\beta=-.15, p<.001)$ are significantly associated with psychological symptoms.

\section{Mediation Analyses}

To test the mediational roles in the association between COVID-19-related feelings and behaviors, thoughts, and precautions taken and psychological symptoms, 95\% biascorrected confidence intervals (BC CI) were calculated, using a bootstrapping method with 2000 re-samples (Shrout \& Bolger, 2002). Estimates, standard errors, and CI's of mediation models are presented in Table 4.

As seen in Table 4, intolerance of uncertainty significantly mediated the relationship of feelings and behaviors related to COVID-19 (B = .41, CI: .30, .51, $p<.01$ ), thoughts about COVID-19 (B = .23, CI: .06, .39, $p<.05)$ and precautions taken related to COVID-19 (B =-.30, CI: $-.51,-.09$, $p<.05)$ with negative metacognition. Additionally, intolerance of uncertainty significantly mediated the relationships of feelings and behaviors related to COVID-19 $(\mathrm{B}=-.12$, CI: $-.15,-.08, p<.01)$, thoughts about COVID-19 (B = $-.07, \mathrm{CI}:-.11,-.02, p<.05)$ and precautions taken related to COVID-19 (B=.09, CI: .03, .15, $p<.05$ ) with psychological resilience. Furthermore, intolerance of uncertainty

Table 2 Descriptives

\begin{tabular}{|c|c|c|c|c|c|c|c|c|c|c|c|}
\hline & $M$ & $S D$ & 1 & 2 & 3 & 4 & 5 & 6 & 7 & 8 & 9 \\
\hline 1. Negative metacognition & 69.92 & 12.86 & - & $.59 * * *$ & $-.22 * * *$ & $.36 * * *$ & $-.34 * * *$ & $.51 * * *$ & $.32 * * *$ & $.20 * * *$ & .04 \\
\hline 2. Intolerance of uncertainty & 75.14 & 22.82 & & - & $-.19 * * *$ & $.36 * * *$ & $-.47 * * *$ & $.60 * * *$ & $.42 * * *$ & $.33 * * *$ & $.16^{* * * *}$ \\
\hline 3. Positive prospections & 49.87 & 9.27 & & & - & -.08 & $.33 * * *$ & $-.25 * * *$ & -.05 & .05 & $.12 * *$ \\
\hline 4. Negative prospections & 69.12 & 20.31 & & & & - & $-.36 * * *$ & $.48 * * *$ & .04 & .04 & $-.10^{*}$ \\
\hline 5. Psychological resilience & 19.49 & 4.76 & & & & & - & $-.47 * * *$ & $-.22 * * *$ & $-.15 * * *$ & -.04 \\
\hline 6. Psychological symptoms & 50.96 & 39.45 & & & & & & - & $.30 * * *$ & $.18 * * *$ & .04 \\
\hline 7. COVID-19 feelings/behaviors & 30.21 & 7.36 & & & & & & & - & $.63 * * *$ & $.53 * * *$ \\
\hline 8. COVID-19 thoughts & 31.11 & 4.84 & & & & & & & & - & $.53 * * *$ \\
\hline 9. COVID-19 precautions & 21.26 & 3.18 & & & & & & & & & - \\
\hline \multicolumn{12}{|c|}{$\begin{array}{l}\text { Note. Standardized path coefficients among variables are presented. All path coefficients are statistically significant. COVID-19 feelings/behaviors: } \\
\text { Feelings and behaviors related to COVID-19; COVID-19 thoughts: Thoughts about COVID-19; COVID-19 precautions: Precautions taken related to } \\
\text { COVID-19. }\end{array}$} \\
\hline
\end{tabular}


Table 3 Model fitness index values

\begin{tabular}{llllllllll}
\hline & $\chi^{2}$ & df & $\begin{array}{l}\chi^{2} / \\
\text { df }\end{array}$ & CFI & GFI & AGFI & RMSEA & ECVI \\
\hline Model 1 & 163.98 & 21 & 7.81 & .91 & .94 & .86 & .11 & $.40<3.00$ \\
Three error associated final model & 70.86 & 18 & $\mathbf{3 . 9 4}$ & $\mathbf{. 9 7}$ & $\mathbf{. 9 7}$ & $\mathbf{. 9 3}$ & $\mathbf{. 0 7}$ & $\mathbf{. 2 3}<3.00$ \\
\hline
\end{tabular}

Note. The values written bold indicate acceptable goodness of fit values after three error associations significantly mediated the relationships of feelings and behaviors related to COVID-19 $(\mathrm{B}=.39, \mathrm{CI}: .27, .52, p<.01)$, thoughts about COVID-19 ( $\mathrm{B}=.21, \mathrm{CI}: .05, .38, p<.05)$ and precautions taken related to COVID-19 $(\mathrm{B}=-.28, \mathrm{CI}$ : $-.51,-.08, p<.05)$ with negative prospections. Intolerance of uncertainty significantly mediated the relationships of feelings and behaviors related to COVID-19 (B = -.10, CI: -.15 , $-.05, p<.01$ ), thoughts about COVID-19 (B =-.05, CI: -.10 , $-.01, p<.05)$ and precautions taken related to COVID-19 $(\mathrm{B}=.07, \mathrm{CI}: .02, .13, p<.05)$ with positive prospections. Intolerance of uncertainty significantly mediated the relationships of feelings and behaviors related to COVID-19 (B = .71, CI: $.48, .99, p<.01)$, thoughts about COVID-19 (B = .39, CI: $.10, .68, p<.05)$ and precautions taken related to COVID-19 $(\mathrm{B}=-.52, \mathrm{CI}:-.91,-.16, p<.05)$ with psychological symptoms. Lastly, negative metacognition ( $\mathrm{B}=.15$, CI: .08, .23, $p<.01)$, psychological resilience $(\mathrm{B}=.12, \mathrm{CI}: .06, .18$, $p<.01)$, negative prospections $(\mathrm{B}=.15, \mathrm{CI}: .10, .21, p<.01)$ and positive prospections $(\mathrm{B}=.03, \mathrm{CI}: .01, .06, p<.05) \mathrm{sig}-$ nificantly mediated the relationship between intolerance of uncertainty and psychological symptoms.

\section{Discussion}

Recent studies on the COVID-19 pandemic have demonstrated that COVID-19 harms mental health (Erdoğdu et al., 2020; Ho et al., 2020; Wang et al., 2020). Although many studies examined the association between COVID-19 and psychological symptoms, to the best of our knowledge, no study has investigated the links between COVID-19-related feelings and behaviors, thoughts, precautions taken and psychological symptoms with an integrative approach in Turkey so far. Hence, there is a critical need to understand the underlying risk factors as well as protective factors to provide effective preventions and interventions for alleviating individuals' psychological symptoms in the context of the COVID-19 pandemic. The present study aimed to investigate the associations of COVID-19-related feelings and behaviors, thoughts, and precautions taken with psychological symptoms via intolerance of uncertainty, negative metacognition, negative prospections as risk factors, and positive prospections, psychological resilience as protective factors during the COVID-19 pandemic. This will be the first study that

Fig. 1 Path model

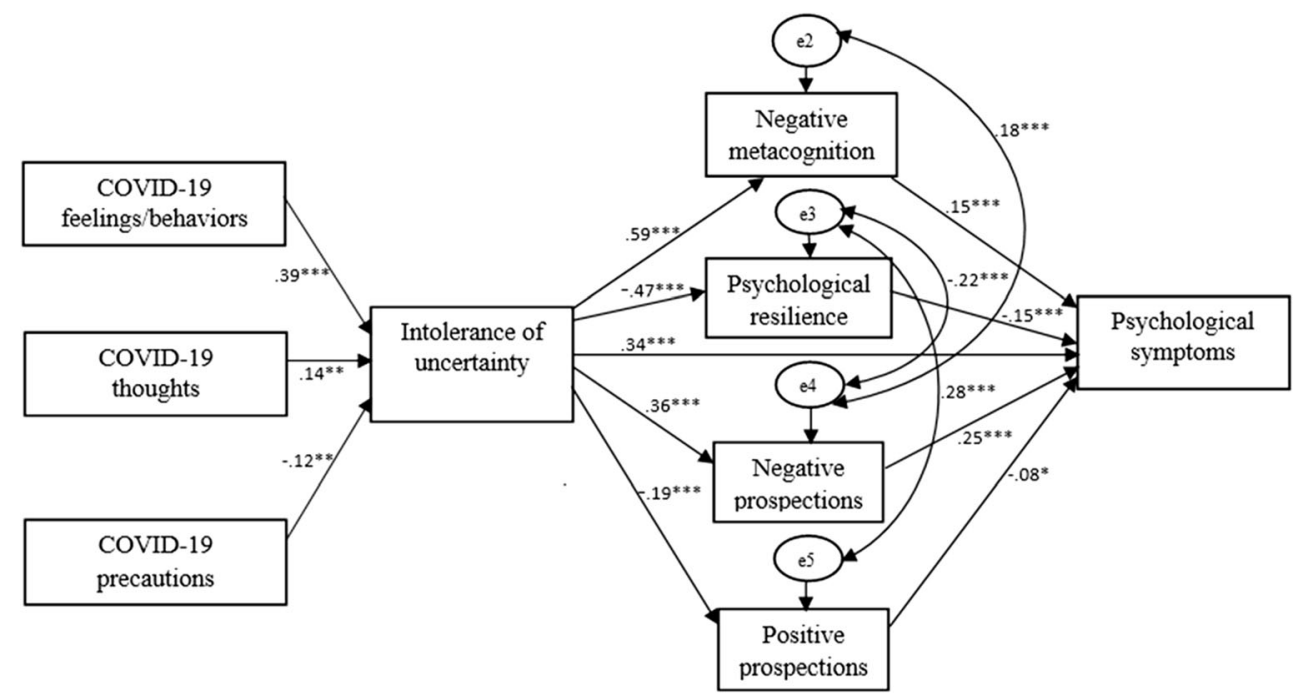

Note. Standardized path coefficients among variables are presented. All path coefficients are statistically

significant COVID-19 feelings/behaviors: Feelings and behaviors related to COVID-19; COVID-19 thoughts:

Thoughts about COVID-19; COVID-19 precautions: Precautions taken related to COVID-19.

$* p<.05 . * * p<.01 . * * * p<.001$. 
Table 4 Estimates of indirect effects

\begin{tabular}{|c|c|c|c|}
\hline Pathway & $\mathrm{B}(\mathrm{SE})$ & Lower bound & Upper bound \\
\hline COVID-19 feelings/behaviors $\rightarrow$ intolerance of uncertainty $\rightarrow$ negative metacognition & $.41 * *(.07)$ & .30 & .51 \\
\hline COVID-19 thoughts $\rightarrow$ intolerance of uncertainty $\rightarrow$ negative metacognition & $.23 *(.10)$ & .06 & .39 \\
\hline COVID-19 precautions $\rightarrow$ intolerance of uncertainty $\rightarrow$ negative metacognition & $-.30 *(.13)$ & -.51 & -.09 \\
\hline COVID-19 feelings/behaviors $\rightarrow$ intolerance of uncertainty $\rightarrow$ psychological resilience & $-.12 * *(.02)$ & -.15 & -.08 \\
\hline COVID-19 thoughts $\rightarrow$ intolerance of uncertainty $\rightarrow$ psychological resilience & $-.07 *(.03)$ & -.11 & -.02 \\
\hline COVID-19 precautions $\rightarrow$ intolerance of uncertainty $\rightarrow$ psychological resilience & $.09 *(.04)$ & .03 & .15 \\
\hline COVID-19 feelings/behaviors $\rightarrow$ intolerance of uncertainty $\rightarrow$ negative prospections & $.39 * *(.08)$ & .27 & .52 \\
\hline COVID-19 thoughts $\rightarrow$ intolerance of uncertainty $\rightarrow$ negative prospections & $.21 *(.10)$ & .05 & .38 \\
\hline COVID-19 precautions $\rightarrow$ intolerance of uncertainty $\rightarrow$ negative prospections & $-.28 *(.13)$ & -.51 & -.08 \\
\hline COVID-19 feelings/behaviors $\rightarrow$ intolerance of uncertainty $\rightarrow$ positive prospections & $-.10 * *(.03)$ & -.15 & -.05 \\
\hline COVID-19 thoughts $\rightarrow$ intolerance of uncertainty $\rightarrow$ positive prospections & $-.05^{*}(.03)$ & -.10 & -.01 \\
\hline COVID-19 precautions $\rightarrow$ intolerance of uncertainty $\rightarrow$ positive prospections & $.07 *(.04)$ & .02 & .13 \\
\hline COVID-19 feelings/behaviors $\rightarrow$ intolerance of uncertainty $\rightarrow$ psychological symptoms & $.71 * *(.16)$ & .48 & .99 \\
\hline COVID-19 thoughts $\rightarrow$ intolerance of uncertainty $\rightarrow$ psychological symptoms & $.39 *(.18)$ & .10 & .68 \\
\hline COVID-19 precautions $\rightarrow$ intolerance of uncertainty $\rightarrow$ psychological symptoms & $-.52 *(.23)$ & -.91 & -.16 \\
\hline Intolerance of uncertainty $\rightarrow$ negative metacognition $\rightarrow$ psychological symptoms & $.15 * *(.04)$ & .08 & .23 \\
\hline Intolerance of uncertainty $\rightarrow$ psychological resilience $\rightarrow$ psychological symptoms & $.12 * *(.04)$ & .06 & .18 \\
\hline Intolerance of uncertainty $\rightarrow$ negative prospections $\rightarrow$ psychological symptoms & $.15 * *(.03)$ & .10 & .21 \\
\hline Intolerance of uncertainty $\rightarrow$ positive prospections $\rightarrow$ psychological symptoms & $.03 *(.01)$ & .01 & .06 \\
\hline
\end{tabular}

Note. COVID-19 feelings/behaviors: Feelings and behaviors related to COVID-19; COVID-19 thoughts: Thoughts about COVID-19; COVID-19 precautions: Precautions taken related to COVID-19.

$* p<.05 . * * p<.01$

examines the mediator roles of risk factors and protective factors together on the associations between COVID-19related feelings and behaviors, thoughts, precautions taken and psychological symptoms with an integrative approach in Turkey.

As hypothesized, we first found that COVID-19-related feelings and behaviors, thoughts, and precautions taken had significantly predicted intolerance of uncertainty. First of all, COVID-19 related feelings and behaviors include feelings such as anxiety, fear, sadness, anger related to the pandemic, and behaviors such as checking the symptoms frequently, following news about the pandemic, and talking about the pandemic often. COVID-19 related thoughts describe the thoughts of individuals regarding the severity, duration, and effects of the pandemic on daily life. COVID-19 related precautions, as the name suggests, refers to the precautions taken such as washing hands frequently, wearing masks, maintaining social distance, and going out far less (Durak Batıgün \& Şenkal Ertürk, 2020). Thus, higher COVID-19-related feelings and behaviors, and thoughts were associated with the greater intolerance of uncertainty; higher COVID-19-related precautions taken was associated with less intolerance of uncertainty. These results suggest that people with dysfunctional coronavirus disease-related feelings and behaviors, and thoughts greatly suffer from an intolerance of uncertainty; people taking coronavirus disease-related precautions have less intolerance of uncertainty. People who have taken coronavirus disease-related precautions might experience lower intolerance of uncertainty, because precautions may give them confidence and a sense of control (Wang et al., 2020). Thus, individuals applying protective and preventive behaviors (e.g., wearing masks, maintaining social distance) more strongly may get some sense of control over uncertain situations, so lower intolerance of uncertainty. Consistently, a recent study found that some precautionary measures (e.g., hand hygiene, wearing masks) were related to a lower psychological effect of the COVID-19 outbreak, lower levels of anxiety, depression, and stress by offering a sense of security (Wang et al., 2020).

Further, as hypothesized, the results of this study showed that intolerance of uncertainty had significantly predicted negative metacognition, psychological resilience, positive prospections, negative prospections, and psychological symptoms, and this variable served as a mediator in the association between COVID-19-related feelings and behaviors, thoughts, and precautions taken and psychological symptoms. We first found that COVID-19-related feelings and behaviors, thoughts, and precautions taken were associated with intolerance of uncertainty, which in turn was positively associated with psychological symptoms. Consistent with these outcomes, a previous study demonstrated that intolerance of uncertainty had a mediator role in the relationship between the 
fear of COVID-19 and positivity. It was suggested that when uncertainty is eliminated from the fear of COVID-19, it would contribute to reducing depression, anxiety, and stress levels, and increasing positivity (Bakioğlu et al., 2020). Another study found that intolerance of uncertainty mediated the relationship between stress-coping strategy's helpless approach and compulsive buying behavior, suggesting that people faced uncertainty due to COVID-19 pandemic, and the strategy they employed to overcome stress and anxiety by adopting helpless coping strategy approach had an indirect effect on their compulsive buying behavior (Çelik \& Köse, 2021). These findings were similar to the results obtained in other studies on the COVID-19 pandemic and its psychological impacts. For instance, in a recent study done by Satici et al. (2020), while a negative relationship was found between the fear of COVID19 and mental wellbeing, a positive relationship was found between the fear of COVID-19 and intolerance of uncertainty. In the same study, intolerance of uncertainty had a significant negative direct effect on mental wellbeing. Furthermore, intolerance of uncertainty was predictive of mental health difficulties such as depression, health anxiety, and generalized anxiety (e.g., Dugas et al., 2005; Kraemer et al., 2016; Rettie \& Daniels, 2020; Voitsidis et al., 2020). Consistently, intolerance of COVID-19-related uncertainty positively predicted negative emotions such as fear, anxiety, and depression, suggesting that individuals with higher COVID-19-related uncertainty were more likely to feel these negative emotions (Dai et al., 2021; Li et al., 2021). In addition, intolerance of uncertainty was positively correlated with COVID-19-related distress (Paluszek et al., 2021). Intolerance of uncertainty is conceptualized as an individual's negative emotions, cognitions, and behaviors in the face of uncertainty (Birrell et al., 2011). Hence, it may be inferred that while COVID-19-related feelings and behaviors, and thoughts increase the intolerance of uncertainty; COVID-19-related precautions taken, which served as control over uncertainty, decrease the intolerance of uncertainty. Another control mechanism over uncertainty for people with high anxiety may be increased pandemicrelated information seeking. As evidence from past pandemics suggests, particularly people with high anxiety may be more likely to seek information related to pandemic due to fear, uncertainty, and loss of control during public health crises, resulting in increased anxiety (Singh et al., 2020). Consistently, people with high anxiety and high intolerance of uncertainty may be more likely to take potentially fatal preventive measures, when they are misinformed (Taylor, 2019).

As hypothesized, we second revealed that intolerance of uncertainty mediated the relationship of COVID-19-related feelings and behaviors, thoughts, and precautions taken with negative metacognition, psychological resilience, positive and negative prospections. Although there is no study investigating the mediator role of intolerance of uncertainty in these relationships within our knowledge, a previous study reported that intolerance of uncertainty was positively correlated with negative metacognition (Thielsch et al., 2015). Besides, the concept of uncertainty is defined as not being able to predict the outcome of an event or any behavior, resulting in potentially affecting people negatively (Sar1, 2007). In other words, it refers to future prospections or the future is not clear. Thus, it becomes clear that intolerance of uncertainty was positively associated with negative prospections and negatively with positive prospections. Furthermore, considering the context of the COVID-19 pandemic, an unfamiliar and chaotic situation, psychological resilience is an ability of a person to manage his/her sense of responsibility in such situations (Di Monte et al., 2020). Intolerance of uncertainty is a psychological feature related to the ability to regulate stress (Di Monte et al., 2020). Accordingly, individuals with higher intolerance of uncertainty may have more difficulty in regulating chaotic and stressful events like the COVID-19 pandemic. Consistently, recent studies found that individuals with higher levels of psychological resilience tend to overcome stressful life events much better compared to individuals with lower psychological resilience (Haktanir et al., 2016; Smith et al., 2017). Similarly, another study found that high resilience was related to less concern about bad outcomes and low general intolerance of uncertainty (Cooke et al., 2013).

Lastly, as hypothesized, we found that psychological resilience and positive prospections were significant predictors of psychological symptoms and mitigated the positive link between intolerance of uncertainty and psychological symptoms in the adult sample. A decrease in intolerance of uncertainty was associated with an increase in psychological resilience and positive prospections, which in turn led to a decrease in psychological symptoms in adults. On the other hand, we found that negative metacognition and negative prospections were significant predictors of psychological symptoms and intensified the negative impacts of intolerance of uncertainty on psychological symptoms in the adult sample. An increase in intolerance of uncertainty was associated with an increase in negative metacognition and negative prospections, which in turn increased the psychological symptoms in adults. Thus, it is suggested that while negative metacognition and negative prospections were psychological risk factors against psychological symptoms during the COVID-19 pandemic, psychological resilience and positive prospections were the protective factors against psychological symptoms during the COVID-19 pandemic. Consistent with these findings, it was revealed that negative expectations about the future have a central role in the maintenance of mental disorders (Rief et al., 2015). A recent study found that negative prospections were positively correlated with depression symptoms, whereas positive prospections were negatively correlated (Ergüler \& Durak Batıün, 2018, 2020). Accordingly, developing effective psychological interventions intended to decrease negative 
expectations about the future that maintain the disorder and increase the positive expectations about the future can reduce mental disorders symptoms (Rief et al., 2015). In addition, a recent study finding showed that more resilient participants had almost 7 times higher odds of flourishing mental health and 9.3 times lower odds of stress levels than less resilient participants (Kavčič et al., 2021). Similarly, in another study it was found that individuals with higher levels of psychological resilience and active coping styles had lower levels of anxiety and depression during the outbreak of COVID-19 (Song et al., 2021). Accordingly, since the COVID-19 pandemic still remains unpredictable, psychotherapeutic interventions should target to enhance psychological resilience both in the general population and specifically in patients with a psychiatric disorder, which results in important implications in terms of mental health outcomes (Verdolini et al., 2021).

\section{Clinical Implications}

The findings in the present study do have some clinical implications relevant for clinicians that aim to relieve COVID-19 associated psychological symptoms. It can be said that the findings obtained in the current study are critical for effective psychological intervention programs to be developed during the COVID-19 pandemic to protect public mental health. More specifically, to enable individuals to manage their psychological health during the COVID-19 pandemic, some risk (intolerance of uncertainty, negative metacognition, negative prospections) and protective factors (psychological resilience, positive prospections) against psychological symptoms are important modifiable variables that should be targeted in clinical practice when developing effective psychological interventions for COVID-19. Therefore, these findings are also of clinical importance. Current and future psychological treatments should focus on these modifiable risk factors, which predict psychological symptoms, and also modifiable protective factors to help ameliorate psychological symptoms in the context of the COVID-19 pandemic. These psychological interventions may effectively enhance individuals' capacity to endure uncertainty for potential future pandemic waves by increasing psychological resilience, positive prospections and by decreasing negative metacognition and negative prospections.

\section{Limitations}

Although our study showed significant results, it is not without limitations. First, our study was based on cross-sectional data, and thus this restricts causal inference and generalizability. It is required for future studies to conduct longitudinal or experimental design to infer a causal relation between COVID-19-related feelings and behaviors, thoughts, and precautions taken and psychological symptoms. Second, the sample consisted of predominantly females $(72.9 \%$ of participants were female) and high level of education (91.4\% of participants' education level was undergraduate and graduate), restricting generalizability of any findings obtained. In the future, researchers should investigate this phenomenon with more equally represented gender groups and equally distributed education level groups. Lastly, the results of the current study have relied on self-report data, which has the risk of source bias (e.g., social desirability and short-term recall). We recommend that future studies should utilize qualitative designs alongside self-report questionnaires or mixed method designs for studying the links between COVID-19-related feelings and behaviors, thoughts, and precautions taken and psychological symptoms in the context of the pandemic. For instance, Online Photovoice (OPV) (see Tanhan \& Strack, 2020) by itself or with some self-report questionnaires could be used to conduct qualitative or mixed method designs to examine this subject.

Notwithstanding these limitations mentioned above, this study reports essential data regarding the psychological effects of COVID-19-related feelings and behaviors, thoughts, and precautions taken and raises clinicians' and researchers' awareness about the protective and risk factors against psychological symptoms to fight such a deadly pandemic. In light of this increased awareness, our findings imply that future psychotherapeutic interventions (e.g., mindfulness-based interventions, psychodynamic interventions, psycho-education about COVID-19 pandemic, digital interventions, cognitive behavioral therapy) will focus on alleviating these risk factors as well as enhancing these protective factors, resulting in relieving COVID-19 associated psychological symptoms.

Taken together, then, this study is the first to examine COVID-19-related feelings and behaviors, thoughts, and precautions taken, multi-dimensionally in the general population during COVID-19, adding to the recent literature on protective and risk factors together against psychological symptoms during uncertain times. The results of this study highlight the roles of both the protective and risk factors in the link between COVID-19-related feelings and behaviors, thoughts, and precautions taken and psychological symptoms.

Code Availability Not applicable.

Authors' Contributions All authors contributed to the study conception and design. Material preparation, data collection and analysis were performed by all authors. The first draft of the manuscript was written by all authors and all authors commented on previous versions of the manuscript. All authors read and approved the final manuscript. All authors contributed equally to editing of the final manuscript.

Funding The authors did not receive support from any organization for the submitted work. 
Data Availability The datasets analysed during the current study are available from the corresponding author on reasonable request.

\section{Declarations}

Ethics Approval This study was performed in line with the principles of the Declaration of Helsinki. Approval was granted by the Ethics Committee of Ankara University.

Consent to Participate Informed consent was obtained from all individual participants included in the study.

\section{Consent for Publication Not applicable.}

Disclosure of Potential Conflicts of Interest On behalf of all authors, the corresponding author states that there is no conflict of interest.

Research Involving Human Participants and/or Animals All procedures performed in studies involving human participants were in accordance with the ethical standards of the institutional and/or national research committee (Ankara University Ethics Committee) and with the 1964 Helsinki declaration and its later amendments or comparable ethical standards.

Informed Consent Informed consent was obtained from all individual participants included in the study.

\section{References}

American Psychological Association. (2012). Building your resilience. Retrieved June 1, 2021, from https://www.apa.org/topics/resilience

Arslan, G., Yıldırım, M., \& Aytaç, M. (2020). Subjective vitality and loneliness explain how coronavirus anxiety increases rumination among college students. Death Studies. https://doi.org/10.1080/ 07481187.2020 .1824204$.

Bakioğlu, F., Korkmaz, O., \& Ercan, H. (2020). Fear of COVID-19 and positivity: Mediating role of intolerance of uncertainty, depression, anxiety, and stress. International Journal of Mental Health and Addiction. https://doi.org/10.1007/s11469-020-00331-y.

Beck, A. T. (1974). The development of depression: A cognitive model. In R. J. Friedman \& M. M. Katz (Eds.), The psychology of depression: Contemporary theory and research (pp. 318-330). John Wiley.

Birrell, J., Meares, K., Wilkinson, A., \& Freeston, M. (2011). Toward a definition of intolerance of uncertainty: A review of factor analytical studies of the intolerance of uncertainty scale. Clinical Psychology Review, 31(7), 1198-1208. https://doi.org/10.1016/j.cpr.2011.07. 009.

Boelen, P. A., \& Reijntjes, A. (2009). Intolerance of uncertainty and social anxiety. Journal of Anxiety Disorders, 23(1), 130-135. https://doi.org/10.1016/j.janxdis.2008.04.007.

Buhr, K., \& Dugas, M. J. (2002). The intolerance of uncertainty scale: Psychometric properties of the English version. Behaviour Research and Therapy, 40(8), 931-945. https://doi.org/10.1016/S00057967(01)00092-4.

Çakıroğlu, S., Ertaş, E., \& Alyanak, B. (2020). Ruh sağlığı ve COVID-19 pandemisi: Dikkate alınması gereken bir konu; uyum bozukluğu ve psikososyal müdahaleler. Türk Psikiyatri Dergisi, 71-73. https:// doi.org/10.5080/u25625.

Carleton, R. N. (2012). The intolerance of uncertainty construct in the context of anxiety disorders: Theoretical and practical perspectives.
Expert Review of Neurotherapeutics, 12(8), 937-947. https://doi. org/10.1586/ern.12.82.

Çelik, S., \& Köse, G. G. (2021). Mediating effect of intolerance of uncertainty in the relationship between coping styles with stress during pandemic (COVID-19) process and compulsive buying behavior. Progress in Neuro-Psychopharmacology and Biological Psychiatry, 110, 1-9. https://doi.org/10.1016/j.pnpbp.2021.110321.

Choi, E., Lee, J., \& Lee, S. A. (2020). Validation of the Korean version of the obsession with COVID-19 scale and the coronavirus anxiety scale. Death Studies, 1-7. https://doi.org/10.1080/07481187.2020. 1833383.

Cooke, G. P., Doust, J. A., \& Steele, M. C. (2013). A survey of resilience, burnout, and tolerance of uncertainty in Australian general practice registrars. BMC Medical Education, 13(2), 1-6. https://doi.org/10. 1186/1472-6920-13-2.

Dai, W., Meng, G., Zheng, Y., Li, Q., Dai, B., \& Liu, X. (2021). The impact of intolerance of uncertainty on negative emotions in COVID-19: Mediation by pandemic-focused time and moderation by perceived efficacy. International Journal of Environmental Research and Public Health, 18(8), 1-13. https://doi.org/10.3390/ ijerph18084189.

Derogatis, L. R. (1992). The brief Symtom inventory (BSI): Administration, scoring and procedures manual-II. Clinical Psychometric Research.

Di Monte, C., Monaco, S., Mariani, R., \& Di Trani, M. (2020). From resilience to burnout: Psychological features of Italian general practitioners during COVID-19 emergency. Frontiers in Psychology, 11, 1-9. https://doi.org/10.3389/fpsyg.2020.567201.

Doğan, T. (2015). Kısa Psikolojik Sağlamlık Ölçeği'nin Türkçe uyarlaması: Geçerlik ve güvenirlik çalışması. The Journal of Happiness \& Well-Being, 3(1), 93-102.

Dörnyei, Z. (2007). Research methods in applied linguistics: Quantitative, qualitative, and mixed methodologies. Oxford University Press.

Dugas, M. J., Marchand, A., \& Ladouceur, R. (2005). Further validation of a cognitive-behavioral model of generalized anxiety disorder: Diagnostic and symptom specificity. Journal of Anxiety Disorders, 19(3), 329-343. https://doi.org/10.1016/j.janxdis.2004.02.002.

Durak Batıün, A., \& Senkal Ertürk, İ. (2020). Multi-dimensional COVID-19 scale development, validity and reliability study. Nesne, 8(18), 406-421. https://doi.org/10.7816/nesne-08-18-04.

Erdoğdu, Y., Koçoğlu, F., \& Sevim, C. (2020). An investigation of the psychosocial and demographic determinants of anxiety and hopelessness during COVID-19 pandemic. Turkish Journal of Clinical Psychiatry, 23(Supp. 1), 24-37. https://doi.org/10.5505/kpd.2020. 35403.

Ergüler, H., \& Durak Batıün, A. (2018). Subjective probability task: Validity and reliability. Turkish Journal of Clinical Psychiatry, 21(2), 168-176. https://doi.org/10.5505/kpd.2017.76376.

Ergüler, H., \& Durak Batıün, A. (2020). Examination of the relationship between depression, future expectations, and several executive function variables. Turkish Journal of Clinical Psychiatry, 23, 266-273. https://doi.org/10.5505/kpd.2020.41033.

George, D., \& Mallery, M. (2010). SPSS for windows a step by step: A simple study guide and reference (10th ed.). Pearson Education, Inc.

Haktanir, A., Lenz, A. S., Can, N., \& Watson, J. C. (2016). Development and evaluation of Turkish language versions of three positive psychology assessments. International Journal for the Advancement of Counselling, 38(4), 286-297. https://doi.org/10.1007/s10447-0169272-9.

Hjemdal, O., Stiles, T., \& Wells, A. (2013). Automatic thoughts and meta-cognition as predictors of depressive or anxious symptoms: A prospective study of two trajectories. Scandinavian Journal of Psychology, 54(2), 59-65. https://doi.org/10.1111/sjop.12010.

Ho, C. S. H., Chee, C. Y. I., \& Ho, R. C. M. (2020). Mental health strategies to combat the psychological impact of COVID-19 beyond 
paranoia and panic. Annals, Academy of Medicine, Singapore, $49(1), 1-6$

Hu, L., \& Bentler, P. M. (1999). Cutoff criteria for fit indexes in covariance structure analysis: Conventional criteria versus new alternatives. Structural Equation Modeling: A Multidisciplinary Journal, 6(1), 1-55. https://doi.org/10.1080/10705519909540118.

Hu, D., Kong, Y., Li, W., Han, Q., Zhang, X., Zhu, L. X., Wan, S. W., Liu, Z., Shen, Q., Yang, J., He, H., \& Zhu, J. (2020). Frontline nurses' burnout, anxiety, depression, and fear statuses and their associated factors during the COVID-19 outbreak in Wuhan, China: A large-scale cross-sectional study. EClinicalMedicine, 24. https://doi. org/10.1016/j.eclinm.2020.100424.

Kavčič, T., Avsec, A., \& Kocjan, G. Z. (2021). Psychological functioning of Slovene adults during the COVID-19 pandemic: Does resilience matter? Psychiatric Quarterly, 92(1), 207-216. https://doi.org/10. 1007/s11126-020-09789-4.

Kraemer, K. M., O’Bryan, E. M., \& McLeish, A. C. (2016). Intolerance of uncertainty as a mediator of the relationship between mindfulness and health anxiety. Mindfulness, 7, 859-865. https://doi.org/10. 1007/s12671-016-0524-x.

Li, Q., Luo, R., Zhang, X., Meng, G., Dai, B., \& Liu, X. (2021). Intolerance of COVID-19-related uncertainty and negative emotions among chinese adolescents: A moderated mediation model of risk perception, social exclusion and perceived efficacy. International Journal of Environmental Research and Public Health, 18(6), 115. https://doi.org/10.3390/ijerph18062864.

Lind, C., \& Boschen, M. J. (2009). Intolerance of uncertainty mediates the relationship between responsibility beliefs and compulsive checking. Journal of Anxiety Disorders, 23(8), 1047-1052. https:// doi.org/10.1016/j.janxdis.2009.07.005.

Luceño-Moreno, L., Talavera-Velasco, B., García-Albuerne, Y., \& Martín-García, J. (2020). Symptoms of posttraumatic stress, anxiety, depression, levels of resilience and burnout in Spanish health personnel during the COVID-19 pandemic. International Journal of Environmental Research and Public Health, 17(15), 1-25. https:// doi.org/10.3390/ijerph17155514.

MacLeod, A. K., Byrne, A., \& Valentine, J. D. (1996). Affect, emotional disorder, and future-directed thinking. Cognition \& Emotion, 10(1), 69-86. https://doi.org/10.1080/026999396380394.

Paluszek, M. M., Asmundson, A. J., Landry, C. A., McKay, D., Taylor, S., \& Asmundson, G. J. (2021). Effects of anxiety sensitivity, disgust, and intolerance of uncertainty on the COVID stress syndrome: A longitudinal assessment of transdiagnostic constructs and the behavioural immune system. Cognitive Behaviour Therapy, 50(3), 191-203. https://doi.org/10.1080/16506073.2021.1877339.

Ran, L., Wang, W., Ai, M., Kong, Y., Chen, J., \& Kuang, L. (2020). Psychological resilience, depression, anxiety, and somatization symptoms in response to COVID-19: A study of the general population in China at the peak of its epidemic. Social Science \& Medicine, 262, 1-6. https://doi.org/10.1016/j.socscimed.2020. 113261.

Reading, A. (2004). The nature of hope. In Hope and despair: How perceptions of the future shape human behavior (pp. 3-14). JHU Press.

Rettie, H., \& Daniels, J. (2020). Coping and tolerance of uncertainty: Predictors and mediators of mental health during the COVID-19 pandemic. American Psychologist, 76, 1-11. https://doi.org/10. 1037/amp0000710

Rief, W., Glombiewski, J. A., Gollwitzer, M., Schubö, A., Schwarting, R., \& Thorwart, A. (2015). Expectancies as core features of mental disorders. Current Opinion in Psychiatry, 28(5), 378-385. https:// doi.org/10.1097/YCO.0000000000000184.

Roepke, A. M., \& Seligman, M. E. (2016). Depression and prospection. British Journal of Clinical Psychology, 55(1), 23-48. https://doi. org/10.1111/bjc.12087.
Şahin, N. H., \& Durak, A. (1994). Kısa Semptom Envanteri: Türk gençleri için uyarlanması. Türk Psikoloji Dergisi, 9(31), 44-56.

Sarı, S. (2007). The investigation of intolerance of uncertainty, beliefs about worry and locus of control as predictors of trait anxiety [unpublished master's thesis]. Hacettepe Üniversitesi Sosyal Bilimler Enstitüsü.

Sarı, S., \& Dă̆ İ. (2009). Belirsizliğe Tahammülsüzlük Ölçeği, Endișe ile ilgili Olumlu İnançlar Ölçeği ve Endișenin Sonuçları Ölçeği'nin Türkçeye uyarlanması, geçerliliği ve güvenilirliği. Anadolu Psikiyatri Dergisi, 10, 261-270.

Satici, B., Saricali, M., Satici, S. A., \& Griffiths, M. D. (2020). Intolerance of uncertainty and mental wellbeing: Serial mediation by rumination and fear of COVID-19. International Journal of Mental Health and Addiction. https://doi.org/10.1007/s11469-02000305-0.

Seligman, M. E., Railton, P., Baumeister, R. F., \& Sripada, C. (2013). Navigating into the future or driven by the past. Perspectives on Psychological Science, 8(2), 119-141. https://doi.org/10.1177/ 1745691612474317.

Shrout, P. E., \& Bolger, N. (2002). Mediation in experimental and nonexperimental studies: New procedures and recommendations. Psychological Methods, 7(4), 422-445. https://doi.org/10.1037// 1082-989X.7.4.422.

Singh, P., Cumberland, W. G., Ugarte, D., Bruckner, T. A., \& Young, S. D. (2020). Association between generalized anxiety disorder scores and online activity among US adults during the COVID-19 pandemic: Cross-sectional analysis. Journal of Medical Internet Research, 22(9), e21490. https://doi.org/10.2196/21490.

Smith, B. W., Dalen, J., Wiggins, K., Tooley, E., Christopher, P., \& Bernard, J. (2008). The brief resilience scale: Assessing the ability to bounce back. International Journal of Behavioral Medicine, 15(3), 194-200. https://doi.org/10.1080/10705500802222972.

Smith, L. B., Lenz, A. S., \& Strohmer, D. (2017). Differential prediction of resilience among individuals with and without a history of abuse. Counseling and Values, 62(1), 106-122. https://doi.org/10.1002/ cvj.12052.

Sohl, S. J., \& Moyer, A. (2009). Refining the conceptualization of a future-oriented self-regulatory behavior: Proactive coping. Personality and Individual Differences, 47(2), 139-144. https:// doi.org/10.1016/j.paid.2009.02.013.

Song, S., Yang, X., Yang, H., Zhou, P., Ma, H., Teng, C., Chen, H., Ou, H., Li, J., Mathews, C. A., Nutley, S., Liu, N., Zhang, X., \& Zhang, N. (2021). Psychological resilience as a protective factor for depression and anxiety among the public during the outbreak of COVID19. Frontiers in Psychology, 11, 1-8. https://doi.org/10.3389/fpsyg. 2020.618509.

Strunk, D. R., Lopez, H., \& DeRubeis, R. J. (2006). Depressive symptoms are associated with unrealistic negative predictions of future life events. Behaviour Research and Therapy, 44(6), 861-882. https://doi.org/10.1016/j.brat.2005.07.001.

T. C. Ministry of Health. (2021). Türkiye günlük koronavirüs tablosu. Retrieved June 1, 2021, from https://covid19.saglik.gov.tr/

Tabachnick, B. G., \& Fidell, L. S. (2001). Cleaning up your act: Screening data prior to analysis. Using Multivariate Statistics, 5, 61-116.

Tanhan, A., \& Strack, R. W. (2020). Online photovoice to explore and advocate for Muslim biopsychosocial spiritual wellbeing and issues: Ecological systems theory and ally development. Current Psychology, 39(6), 2010-2025. https://doi.org/10.1007/s12144020-00692-6.

Taylor, S. (2019). The psychology of pandemics: Preparing for the next global outbreak of infectious disease. Cambridge Scholars Publishing.

Thielsch, C., Andor, T., \& Ehring, T. (2015). Metacognitions, intolerance of uncertainty and worry: An investigation in adolescents. 
Personality and Individual Differences, 74, 94-98. https://doi.org/ 10.1016/j.paid.2014.10.004.

Tosun, A., \& Irak, M. (2008). Adaptation, validity, and reliability of the metacognition Questionnaire-30 for the Turkish population, and its relationship to anxiety and obsessive-compulsive symptoms. Turkish Journal of Psychiatry, 19(1), 67-80.

Verdolini, N., Amoretti, S., Montejo, L., García-Rizo, C., Hogg, B., Mezquida, G., Rabelo-da-Ponte, F. D., Vallespir, C., Radua, J., Martinez-Aran, A., Pacchiarotti, I., Rosa, A. R., Bernardo, M., Vieta, E., Torrent, C., \& Sol'e, B. (2021). Resilience and mental health during the COVID-19 pandemic. Journal of Affective Disorders, 283, 156-164. https://doi.org/10.1016/j.jad.2021.01. 055 .

Vilhauer, J. S., Young, S., Kealoha, C., Borrmann, J., IsHak, W. W., Rapaport, M. H., Hartoonian, N., \& Mirocha, J. (2012). Treating major depression by creating positive expectations for the future: A pilot study for the effectiveness of future-directed therapy (FDT) on symptom severity and quality of life. CNS Neuroscience \& Therapeutics, 18(2), 102-109. https://doi.org/10.1111/j.17555949.2011.00235.x.

Voitsidis, P., Nikopoulou, V. A., Holeva, V., Parlapani, E., Sereslis, K., Tsipropoulou, V., Karamoizi, P., Giazkoulidou, A., Tsopaneli, N., \& Diakogiannis, I. (2020). The mediating role of fear of COVID-19 in the relationship between intolerance of uncertainty and depression. Psychology and Psychotherapy: Theory, Research and Practice. https://doi.org/10.1111/papt.12315.
Wang, C., Pan, R., Wan, X., Tan, Y., Xu, L., Ho, C. S., \& Ho, R. C. (2020). Immediate psychological responses and associated factors during the initial stage of the 2019 coronavirus disease (COVID-19) epidemic among the general population in China. International Journal of Environmental Research and Public Health, 17(5), 125. https://doi.org/10.3390/ijerph17051729.

Wells, A., \& Cartwright-Hatton, S. (2004). A short form of the metacognitions questionnaire: Properties of the MCQ-30. Behaviour Research and Therapy, 42(4), 385-396. https://doi.org/ 10.1016/S0005-7967(03)00147-5.

Wells, A., \& Papageorgiou, C. (1998). Relationships between worry, obsessive-compulsive symptoms and meta-cognitive beliefs. Behaviour Research and Therapy, 36(9), 899-913. https://doi.org/ 10.1016/S0005-7967(98)00070-9.

Worldometer. (2021). COVID-19 coronavirus pandemic. Retrieved June 1, 2021, from https://www.worldometers.info/coronavirus/

Yıldırım, M., \& Solmaz, F. (2020). COVID-19 burnout, COVID-19 stress and resilience: Initial psychometric properties of COVID-19 burnout scale. Death Studies, 1-9. https://doi.org/10.1080/ 07481187.2020 .1818885 .

Publisher's Note Springer Nature remains neutral with regard to jurisdictional claims in published maps and institutional affiliations. 